\title{
A utilização do percutor em pedra branda na debitagem lamelar durante o Magdalenense na Estremadura portuguesa
}

\author{
Cristina Gameiro
}

UNIARQ - Faculdade de Letras da Universidade de Lisboa, Alameda da Universidade, 1600-214 Lisboa, Portugal. Email: gameiro.cristina@gmail.com

\begin{abstract}
Resumo:
O desenvolvimento de programas direccionados de talhe experimental em sílex permitiu identificar os estigmas relacionados com a utilização de percutores em pedra branda. Pelegrin (2000) explorou os limites e constrangimentos da utilização deste tipo de percutores e desde a publicação dos critérios distintivos, que permitem reconhecer esta técnica no material arqueológico, ela foi identificada em vários sítios e em diferentes cronologias na Europa e no Próximo Oriente. A identificação fortuita de estigmas evocativos da utilização de percutores em pedra branda na colecção lítica da camada 3 da Lapa dos Coelhos motivou um registo sistemático, desses atributos, durante o estudo de outras colecções magdalenenses da Estremadura portuguesa. Foram observados e registados os seguintes atributos: tipo de talão (cortical, liso, diedro, facetado, microfacetado, linear, punctiforme, esmagado e retocado), presença de labiado, vestígios de abrasão (ligeira ou marcada), presença de esquirolamento do bolbo, presença de fissuração do cone de percussão, existência de rugas finas concêntricas a partir do bolbo de percussão e presença de linha do talão irregular. A análise e quantificação destes estigmas de percussão permitiu identificar um número significativo de peças com evidência de debitagem por percutor brando (orgânico e mineral) mas a associação recorrente de caracteres distintivos leva a crer que a utilização de percutores em pedra branda terá sido significativa. Não dispomos de dados para uma comparação efectiva de toda a sequência regional do Paleolítico Superior, contudo, na amostra observada a utilização de um percutor de pedra branda parece ter aumentado a partir do Magdalenense final. Apesar de preliminares estes dados devem ser tidos em conta, uma vez que, esta informação é fundamental para a reconstituição das escolhas técnicas efectuadas no passado.
\end{abstract}

Palavras-chave: Portugal; Magdalenense; debitagem lamelar; tipos de percussão; percutor em pedra branda

\section{Introdução}

A técnica designa a modalidade de debitagem englobando o modo de aplicação da força, o tipo de percutor e o gesto ou a posição de talhe, e a mesma técnica pode ser utilizada em diferentes métodos de debitagem, entendidos como o agenciamento sequencial do processo

Published by the School of History, Classics and Archaeology, University of Edinburgh ISSN: 2055-0472. URL: http://journals.ed.ac.uk/lithicstudies/

This work is licensed under a Creative Commons Attribution 2.5 UK: Scotland License. 
técnico pré-determinado ou cadeia operatória (Inizan et al. 1995). A leitura da técnica de percussão (utilização de um percutor para debitar ou afeiçoar) deve fazer parte da abordagem tecnológica de uma colecção lítica. O desenvolvimento do talhe experimental tem tornado mais eficaz a identificação das técnicas de percussão. No âmbito dos trabalhos pioneiros de Bordes e Crabtree (1969) ou de Tixier (1967) foram reproduzidas experimentalmente e identificados os estigmas de quatro tipos de técnicas de percussão: directa com percutor de pedra, directa com percutor orgânico (haste, osso ou alguns tipos de madeira), indirecta (com utensílio intermédio de haste, osso, alguns tipos de madeira ou metal) e por pressão (simples ou com alavanca) (Tixier et al. 1980; Inizan et al. 1995). O percutor em pedra pode ser de uma matéria-prima dura (seixos de quartzo, quartzito, basalto ou sílex) ou branda (seixos de calcário, de sílex com córtex espesso, grés, arenito ou xisto). Durante o início dos anos 80 do século XX, a utilização de percutor em pedra branda foi identificada por E. Callahan para a debitagem de obsidiana e B. Madsen suspeitou que tal também pudesse ter sido utilizado na debitagem de lâminas em sílex durante o Tardiglaciar na Dinamarca (Pelegrin \& Inizan 2013). Este reconhecimento conduziu Madsen e Pelegrin ao desenvolvimento de programas direccionados de talhe experimental de sílex com percutor em pedra branda, identificando os estigmas, explorando os limites e constrangimentos da utilização deste tipo de percutores e culminando com a publicação dos critérios distintivos que permitem reconhecer esta técnica no material arqueológico (Pelegrin 2000). Posteriormente, esta técnica foi identificada em colecções do Castelperronense (Bachellerie et al. 2007), do Gravetense francês (Klaric 2003), do Solutrense da região de Yonne, França (Renard 2002), do Tardiglaciar da região parisiense (Bodu 2000; Valentin 2000; 2008), do Epigravetense italo-provençal (Bracco 1997) e do Epipaleolítico do levante (Pelegrin \& Inizan 2013).

\subsection{Estado da arte}

Tradicionalmente, nos estudos de colecções líticas portuguesas não tem sido dada muita atenção ao reconhecimento da utilização deste tipo de percutor em pedra branda. Em obras didácticas, esta opção técnica, ou não é mencionada (Gibaja \& Carvalho 2012) ou tem sido apenas sucintamente referida (Almeida et al. 2003; Aubry et al. 1998). De facto, as peças debitadas através da utilização de um percutor em pedra branda podem apresentar estigmas típicos da percussão directa dura e estigmas típicos da percussão directa branda, ou seja os estigmas diagnósticos da percussão com pedra branda sobrepõem-se ou constituem uma categoria intermédia (Tabela 1). Estudos morfométricos recentes levados a cabo em colecções de talhe experimental têm comprovado a sobreposição de características, no entanto, confirmam a pertinência da utilização destes resultados para identificar tendências genéricas das técnicas de percussão (Dibble \& Pelcin 1995; Damlien 2015). Conscientes destas limitações, continuamos a considerar válidos os elementos provenientes da observação dos diferentes estigmas em peças produzidas recorrendo ao talhe experimental, considerando esta informação fundamental para a reconstituição das escolhas técnicas efectuadas no passado. Em Portugal, a dificuldade de acesso a colecções de referência de talhe experimental que possibilitem, não só a comparação com o referencial arqueológico, mas também uma aprendizagem do tipo de critérios distintivos de utilização deste tipo de percutores, torna ainda mais difícil esta via de análise. Contudo, «como só podemos reconhecer aquilo que conhecemos» (Pelegrin 2000: 74), consideramos útil a publicação deste estudo, a divulgação de documentação fotográfica elucidativa, assim como a apresentação de terminologia em língua portuguesa (para vocabulário geralmente publicado noutras línguas). 
Tabela 1. Resumo dos estigmas diagnosticantes dos diferentes tipos de percutor, representando a cinzento escuro as características comuns à utilização de percutor em pedra dura e em pedra branda ou pedra branda e orgânico. Segundo os dados de talhe experimental apresentados por Texier et al. (1980), Inizan et al. (1995), J. Pelegrin (2000), Valentin (2000) e Damlien (2015).

Table 1. Summary of the diagnostic stigmata from different types of hammer, representing in dark grey overlapped characteristics to the use of hard hammerstone and soft hammerstone or soft hammerstone and organic hammer. According to the experimental data presented by Texier et al. (1980), Inizan et al. (1995), J. Pelegrin (2000), Valentin (2000) e Damlien (2015).

\begin{tabular}{|c|c|c|c|c|}
\hline \multicolumn{5}{|c|}{ Tipo de Percutor } \\
\hline Pedra dura & \multicolumn{2}{|c|}{ Pedra branda } & \multicolumn{2}{|c|}{ Orgânico } \\
\hline $\begin{array}{c}\text { Talões espessos (lisos ou } \\
\text { facetados) }\end{array}$ & \multicolumn{4}{|c|}{\begin{tabular}{|c|c|c|} 
& $\begin{array}{c}\text { Talões pouco espessos mas } \\
\text { visíveis }\end{array}$ & \\
\end{tabular}} \\
\hline $\begin{array}{l}\text { Ponto de impacto nítido e } \\
\text { bolbo proeminente }\end{array}$ & \multicolumn{2}{|c|}{$\begin{array}{l}\text { Ponto de impacto visível mas } \\
\text { discreto }\end{array}$} & \multicolumn{2}{|c|}{$\begin{array}{c}\text { Ausência de ponto de } \\
\text { impacto nítido e bolbo pouco } \\
\text { proeminente ou ausente }\end{array}$} \\
\hline \multirow[t]{2}{*}{$\begin{array}{l}\text { Fissuração do cone de } \\
\text { percussão criada pelo } \\
\text { contacto com o percutor }\end{array}$} & \multicolumn{2}{|c|}{$\begin{array}{l}\text { Fissuração incompleta do cone } \\
\text { de percussão }\end{array}$} & & \\
\hline & \multicolumn{3}{|c|}{ Labiado } & \\
\hline \multirow[t]{3}{*}{ Ângulos de $60 \circ$ a 900} & \multicolumn{2}{|c|}{ Ângulos entre 700 e 85을 } & \multicolumn{2}{|c|}{ Ângulos $<80$ o } \\
\hline & \multicolumn{2}{|c|}{ Esquirolamento do bolbo } & & \\
\hline & \multicolumn{2}{|c|}{$\begin{array}{l}\text { Produtos debitados } \\
\text { tendencialmente rectilíneos }\end{array}$} & & \\
\hline \multicolumn{5}{|c|}{ Dois ou três pontos de impacto } \\
\hline \multirow{2}{*}{\multicolumn{2}{|c|}{$\begin{array}{l}\text { Micro-rugas finas e concêntricas } \\
\text { nos primeiros mm }\end{array}$}} & \multirow{2}{*}{\multicolumn{2}{|c|}{ Abrasão necessária }} & \\
\hline & & & & \\
\hline & & & \multicolumn{2}{|c|}{ Produtos debitados finos } \\
\hline
\end{tabular}

\subsection{Apresentação dos sítios analisados}

Neste artigo apresentaremos dados relativos ao tipo de percussão utilizada na produção de suportes lamelares durante o Magdalenense na Estremadura Portuguesa. Os materiais líticos analisados provêm de 3 sítios arqueológicos: Lapa dos Coelhos, Abrigo 1 de Vale de Covões e Cabeço de Porto Marinho (Figura 1). Estes sítios localizam-se na Estremadura portuguesa, uma região litoral situada entre dois rios: o Tejo ao Sul e o Mondego ao Norte. Esta região situa-se na orla meso-cenozoica ocidental, uma unidade morfoestrutural cuja origem está relacionada com a abertura do oceano Atlântico. O substrato geológico é constituído por rochas sedimentares e abundam as rochas carbonatadas carsificadas. Algumas destas formações geológicas (Bajociano, Oxfordiano e Cenomaniano) são ricas em sílex. Seixos de quartzo e quartzito, rochas provenientes do maciço antigo, podem ser recuperados nos leitos fluviais ou em cascalheiras de origem detrítica em toda a região (Aubry et al. 2016).

O Abrigo 1 de Vale Covões (Soure) situa-se a cerca de 300m de altitude, no bordo ocidental do maciço da Sicó. O sítio foi sondado em 2001 e escavado em 2005 por T. Aubry. As camadas 3 e 4 foram atribuídas ao Magdalenense final. Nas imediações existe sílex de média qualidade (bajociano) e o sílex cenomaniano e oxfordiano de boa qualidade está disponível a mais de 40km (Gameiro et al. 2008; Aubry et al. 2016). 

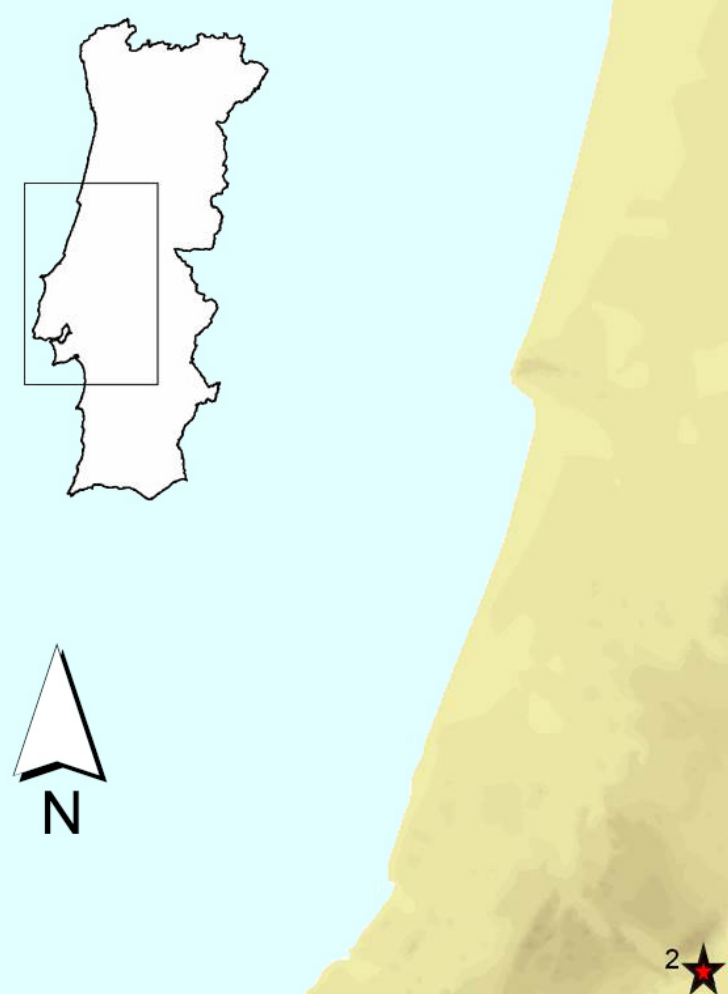

3 负

0

$50 \mathrm{~km}$

Figura 1. Localização dos sítios arqueológicos: 1 - Abrigo 1 de Vale de Covões; 2- Lapa dos Coelhos; 3- Cabeço de Porto Marinho I

Figure 1. Location of the archaeological sites: 1 - Abrigo 1 de Vale de Covões; 2- Lapa dos Coelhos; 3- Cabeço de Porto Marinho I 
A Lapa dos Coelhos (Torres Novas), é uma pequena cavidade $(<10 \mathrm{~m} 2)$ pertencente ao sistema cársico do Rio Almonda situada a cerca de 300m de altitude num encosta bruta (escarpa de falha) sobranceira à nascente deste mesmo rio. A escavação foi dirigida por F. Almeida e J. Correia entre 1997 e 2010 e as camadas 3 e 4 foram atribuídas respectivamente ao Magdalenense final e ao Magdalenense superior (Almeida et al. 2004; Gameiro 2012; Gameiro et al. 2013; Gameiro et al. 2017). Nas imediações existe sílex de média qualidade (bajociano) mas o sílex cenomaniano e oxfordiano de boa qualidade está disponível a cerca de 10km (Gameiro et al. 2008; Aubry et al. 2016).

O Cabeço de Porto Marinho (Rio Maior) é um sítio de ar livre, situado ao Norte da Serra de Montejunto e ao Sudeste da Serra dos Candeeiros, numa área que corresponde a uma zona de passagem entre os maciços montanhosos e o litoral e, praticamente em cima, de depósitos miocénicos ricos em sílex cenomaniano (em posição secundária). Foi escavado no âmbito de um projecto luso-americano por A. Marks, J. Zilhão e N. Bicho entre 1988 e 1994 (Marks \& Mishoe 1997; Zilhão et al. 1995). Apresentaremos dados relativos ao nível inferior (Magdalenense antigo) e ao nível superior (Magdalenense final) do locus I (Tabela 2).

Tabela 2. Datações radiométricas correspondentes às camadas dos sítios arqueológicos apresentados: VCA1 Abrigo 1 de Vale Covões (Aubry et al. 2008); CLH - Lapa dos Coelhos (Almeida et al. 2004); CPM I - Cabeço de Porto Marinho I (Zilhão 1997).

Table 2. Radiometric dates corresponding to the layers of the archaeological sites presented: VCA1 - Abrigo 1 de Vale Covões (Aubry et al. 2008); CLH - Lapa dos Coelhos (Almeida et al. 2004); CPM I - Cabeço de Porto Marinho I (Zilhão 1997).

\begin{tabular}{lccc}
\hline Proveniência & Ref. Laboratório & Amostra & Data BP \\
\hline VCA 1 - camada 4 & Beta-201014 & Micro-carvão & $10020 \pm 40$ \\
CLH - camada 3 & GrN-18376 & Frag. osso - Cervus elaphus & $11660 \pm 60$ \\
CLH - camada 4 & GrN-18377 & Carvão - Pinus sylvestris & $12240 \pm 60$ \\
CPM I - nível inf. & ICEN-542 & Carvão - lareira & $15820 \pm 400$ \\
CPM I - nível inf. & SMU-2015 & Carvão & $16340 \pm 420$ \\
CPM I - nível sup. & SMU-2011 & Carvão & $11680 \pm 60$ \\
CPM I - nível sup. & ICEN-687 & Carvão & $12220 \pm 110$ \\
\hline
\end{tabular}

Em relação à funcionalidade dos sítios, o Cabeço de Porto Marinho tem sido interpretado como um acampamento base de função residencial e tanto a Lapa dos Coelhos como o Abrigo 1 de Vale Covões são considerados sítios de acampamento temporário, provavelmente relacionados com actividades cinegéticas (Gameiro, 2012; Gameiro et al., 2017).

\section{Metodologia}

Durante a realização de um trabalho académico (Gameiro 2003) fomos sensibilizados por B. Valentin para esta problemática, bastante em voga, depois da publicação de Pelegrin (2000). Por outro lado, a frequência de aulas de Tecnologia Lítica, leccionadas por J. Pelegrin, constituiu uma oportunidade de aceder a colecções experimentais. A formação teórica, aliada ao conhecimento obtido com o manuseamento de peças obtidas através do talhe experimental, alicerçou a nossa formação. Durante o estudo do numeroso conjunto de lamelas da camada 3 da Lapa dos Coelhos, culturalmente atribuível ao Magdalenense final (Tabela 2), identificámos a recorrência de estigmas relacionáveis com a utilização do percutor em pedra branda. As nossas suspeitas foram validadas por B. Valentin que observou um conjunto significativo de lamelas em sílex. A identificação de estigmas diagnosticantes, em conjuntos pouco numerosos ou em peças isoladas, pode ser pouco fiável, no entanto, estávamos perante um conjunto bastante significativo: 238 lamelas brutas e 119 lamelas retocadas. Ou seja, num total de 357 lamelas em sílex, foi possível observar a parte proximal (peças inteiras ou 
fragmentos proximais) e registar os atributos relacionáveis com as técnicas de percussão. Observámos e registámos os seguintes atributos: tipo de talão (cortical, liso, diedro, facetado, microfacetado, linear, punctiforme, esmagado e retocado), presença de labiado, vestígios de abrasão (ligeira ou marcada), presença de esquirolamento do bolbo, presença de fissuração do cone de percussão, existência de rugas finas concêntricas a partir do bolbo de percussão e presença de linha do talão irregular. Todos estes atributos foram documentados por observação de peças experimentais (Pelegrin 2000).

No âmbito de um trabalho mais alargado, sobre a variabilidade regional das indústrias líticas do tardiglaciar em Portugal (Gameiro 2012), observámos e registámos os mesmos atributos durante o estudo de outros conjuntos líticos. Para além dos dados relativos à camada 3 da Lapa dos Coelhos, incluímos nessa análise, os conjuntos lamelares provenientes da camada 4 da Lapa dos Coelhos, dos níveis Superior e Inferior do Cabeço de Porto Marinho e das camadas 3 e 4 do Abrigo 1 de Vale de Covões. Num total de 1303 peças (lamelas brutas e retocadas) foi possível observar o talão (peças inteiras ou fragmentos proximais). As amostras estudadas variam significativamente em termos de número e nos conjuntos mais reduzidos os dados apresentados são, obviamente, menos representativos. Apesar de em alguns conjuntos, por exemplo na camada 4 da Lapa dos Coelhos, constarem lamelas em quartzo, seleccionámos para este estudo, relativo aos tipos de percussão, apenas as lamelas em sílex. Apesar de ter sido utilizado sílex com proveniências diferentes, e portanto com características físicas distintas, consideramos que o grau de semelhança física será mais semelhante entre diferentes tipos de sílex do que entre sílex e outras matérias-primas como o quartzo, por exemplo.

\section{Resultados}

Tal como na generalidade dos contextos magdalenenses em território português, em todos os conjuntos líticos estudados a debitagem foi orientada para a produção de lascas e lamelas (Zilhão 1997; Bicho 2000; Gameiro 2012). A produção intencional de lâminas é praticamente inexistente e a maioria dos suportes classificados como tal foram provavelmente produzidos durante uma fase inicial da debitagem lamelar. As lamelas retocadas constituem sempre cerca de 30\% da utensilagem mas foram utilizadas metodologias distintas de escavação e crivagem nos diferentes sítios. A variedade tipológica das lamelas retocadas aumenta ao longo do Magdalenense (Zilhão 1997; Bicho 2000; Gameiro 2012). No que concerne a produção dos suportes lamelares: os volumes foram escolhidos antevendo a possibilidade de utilização da sua morfologia e das suas superfícies naturais; as modalidades de preparação dos volumes são sempre simples (a técnica de crista é raramente utilizada) e são escolhidos diedros naturais ou frequentemente arestas de uma lasca para iniciar a debitagem (Figura 2). Neste caso, os suportes produzidos são típicos resíduos de golpe de buril, identificáveis pela presença de vestígios da face inferior da lasca. Nas colecções analisadas encontrámos este tipo de suporte entre os exemplares retocados e por essa razão não foram distinguidos dos restantes suportes lamelares (Gameiro 2012).

Os planos de percussão são raramente facetados. Frequentemente uma face plana natural do volume é utilizada como plano de percussão e por vezes o levantamento de uma grande lasca cria uma superfície regular a utilizar como plano de percussão. Uma ligeira abrasão da cornija é relativamente frequente (30\%). Em geral, a reduzida dimensão dos volumes e a fraca recorrência das séries de debitagem não exigem operações de manutenção das convexidades propícias ao talhe. A debitagem é tendencialmente unipolar. A exploração intensa da matériaprima conduz a núcleos de dimensões muito reduzidas (por vezes inferiores a $2 \mathrm{~cm}$ ) e origina núcleos com várias superfícies de debitagem e vários planos de percussão mas estes são sempre sucessivos (opostos ou cruzados) ou do tipo principal-secundário, ou seja com um 
plano de debitagem principal e um outro plano de percussão utilizado apenas para (raras) operações de manutenção (Gameiro, 2012; 2013).

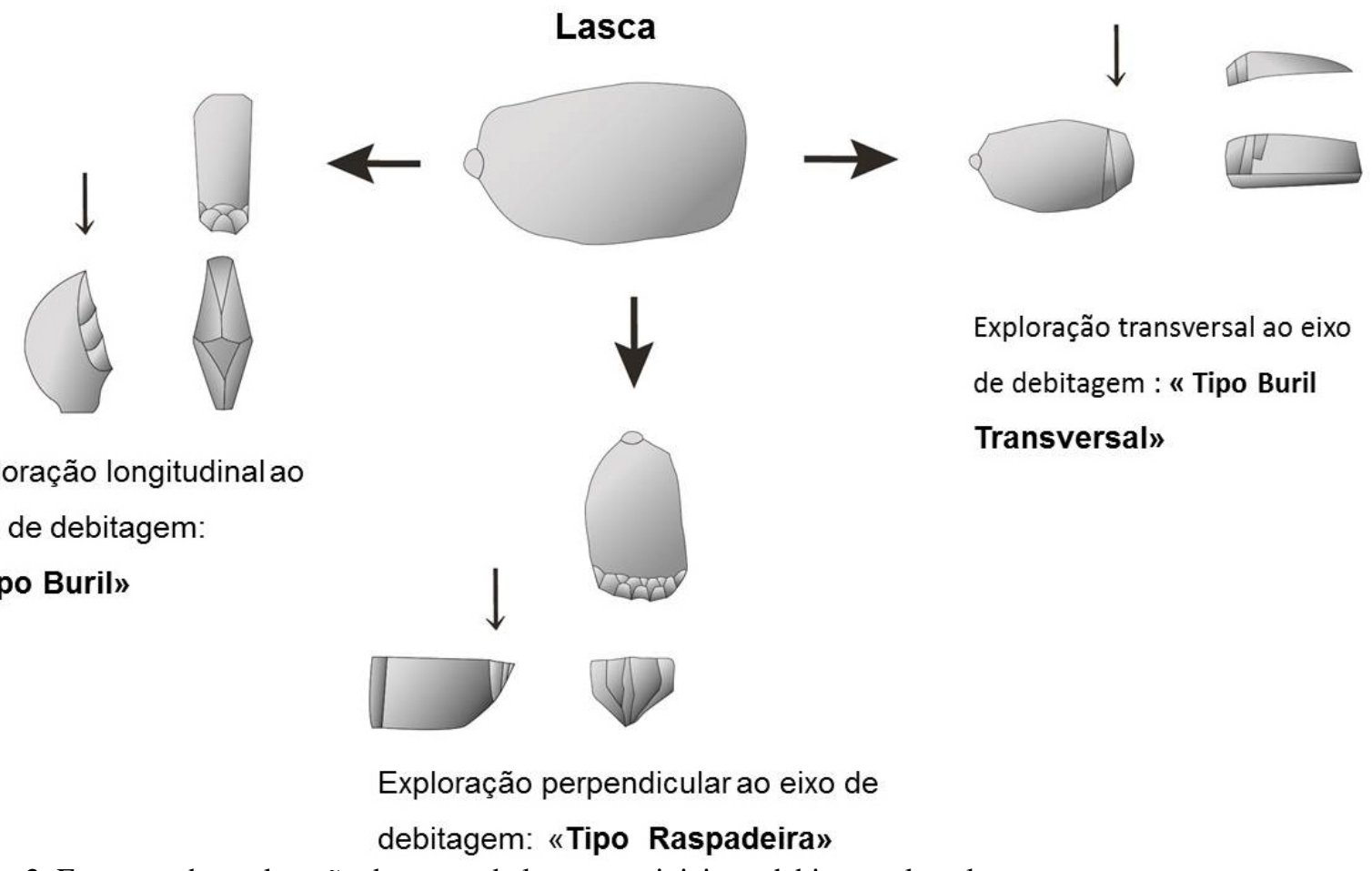

Figura 2. Esquema de exploração de aresta de lasca para iniciar a debitagem lamelar.

Figure 2. Schematic drawing showing exploitation of the flake edge to start bladelet debitage.

A existência de lacunas estratigráficas ou de hiatos de ocupação dos sítios conhecidos entre 18000 e 16000 BP e entre 14000 e 12500 BP (Zilhão 1997) torna mais difícil compreender as dinâmicas inerentes à variabilidade diacrónica da utensilagem lítica utilizada pelos grupos que habitaram o território hoje português durante o Tardiglaciar. Os sítios datados do Magdalenense antigo são raros, o Magdalenense médio continua por caracterizar e a maioria dos sítios conhecidos situam-se no espectro de datações indicada para o Bolling, Allerod e o Dryas III (Gameiro 2012; 2013).

\section{Magdalenense antigo}

Este período encontra-se mal caracterizado em território português. O conjunto lítico do nível inferior do Cabeço de Porto Marinho I constitui um dos raros testemunhos, com datações absolutas, deste período. O conjunto lítico é pouco numeroso mas os materiais provêm de um nível onde foi identificada uma estrutura de combustão. Nesta fase as lamelas retocadas são tendencialmente de morfologia rectangular e o retoque apenas regulariza o bordo, não afectando substancialmente a largura do suporte (Gameiro 2012; 2013). A debitagem sobre aresta de lasca é pouco significativa e consequentemente a percentagem de lamelas de buril também. Morfologicamente, a esmagadora maioria das peças apresenta secção trapezoidal, bordos paralelos e perfil direito. Em 102 peças foi possível observar o talão e descrever caracteres relativos ao tipo de percutor utilizado. A maioria dos talões é de tipo liso (44\%) ou linear (14\%) mas os talões esmagados (17\%) e os punctiformes também estão bem representados (9\%) (Figura 3). Uma ligeira abrasão foi identificada em $26 \%$ das peças e noutros 22\% a abrasão é evidente. Cerca de $41 \%$ dos talões apresentam labiado. $\mathrm{O}$ esquirolamento do bolbo (20\%), a fissuração do cone de percussão (8\%), a presença de rugas finas concêntricas (4\%) e a existência de uma linha do talão irregular (2\%) são estigmas 
identificados. A fraca representatividade do conjunto obriga a alguma prudência no avanço de conclusões sobre o tipo de percutor utilizado. Contudo, parece-nos ser possível avançar que a percussão branda (orgânica ou mineral) terá sido a opção técnica mais utilizada. Ainda que discretos, existem alguns indicadores que nos permitem aferir a utilização de um percutor em pedra branda.

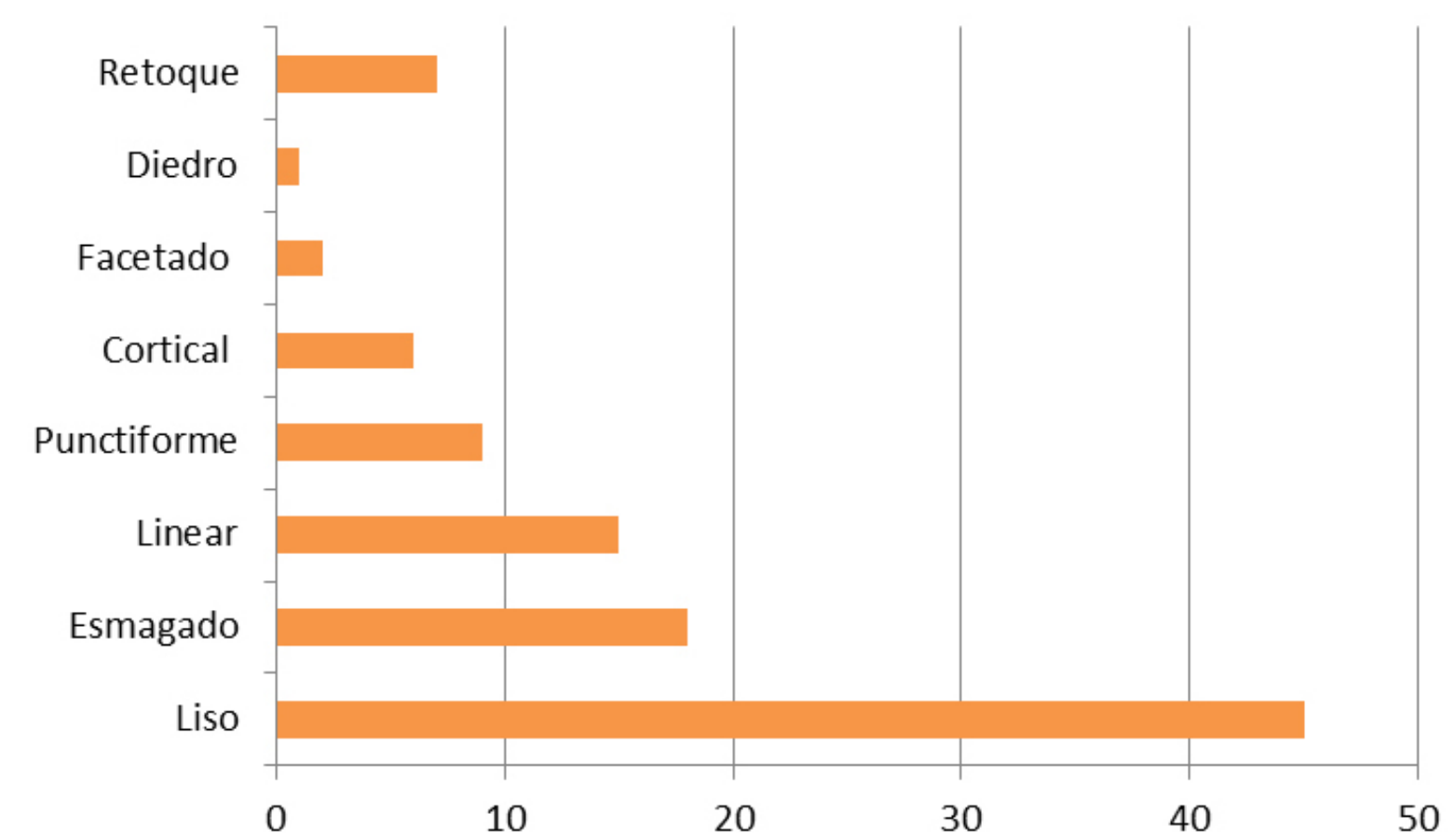

Figura 3. Magdalenense antigo: tipos de talão identificados no conjunto lítico do nível inferior do Cabeço de Porto Marinho I.

Figure 3. Ancient Magdalenian: butt types identified in the lithic assemblage of the lower level of Cabeço de Porto Marinho I.

Nesta fase incluímos a ocupação da camada 4 da Lapa dos Coelhos e do nível superior do Cabeço de Porto Marinho I. O conjunto proveniente da camada 4 da Lapa dos Coelhos é constituído por apenas 57 peças. A maioria dos talões é de tipo esmagado (42\%) ou punctiforme (16\%) (Figura 4), e a frequência da prática da abrasão (ligeira -39\% ou muito evidente-25\%) e a presença de labiado (58\%) são elevados. Estes elementos parecem advogar a favor de uma percussão com percutor bando orgânico. A identificação de 4 casos (7\%) de esquirolamento do bolbo, a juntar às características anteriormente avançadas, pode significar a utilização esporádica de um percutor em pedra branda.

\section{Magdalenense superior}

Analisámos 728 peças provenientes do nível superior do Cabeço de Porto Marinho I. A maioria dos talões observados é de tipo liso (34\%) ou linear (17\%), no entanto os talões de tipo punctiforme (13\%) e esmagado (20\%) também estão bem representados. A utilização da abrasão foi constatada em $42 \%$ das peças (sendo que em $33 \%$ dos casos se trata de uma ligeira abrasão) e a ocorrência de labiado em $64 \%$ exemplares. A linha irregular do talão foi identificada uma única vez. O esquirolamento do bolbo está presente em $17 \%$ das peças e foi notada uma fissuração do cone de percussão em 30\% das lamelas observadas. A frequência de fissurações do cone de percussão nesta série contrasta marcadamente com o verificado nas outras colecções. Os dados apresentados parecem indicar a utilização de um percutor brando e parece-nos provável que a pedra branda tinha sido uma opção frequente. 


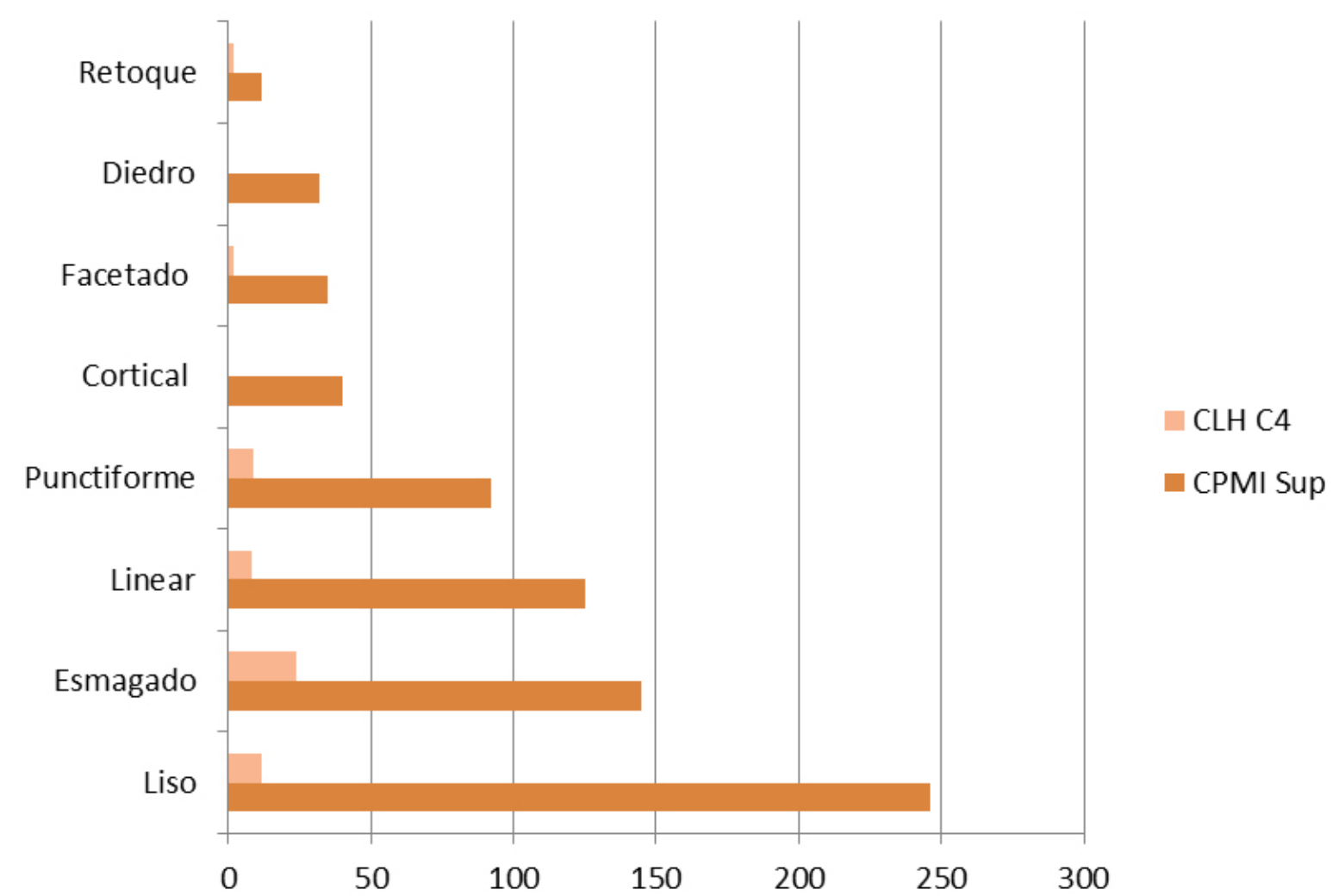

Figura 4. Magdalenense superior : tipos de talão identificados nos conjuntos líticos do nível superior do Cabeço de Porto Marinho I e na camada 3 da Lapa dos Coelhos.

Figure 4. Upper Magdalenian: butt types identified in the lithic assemblage of the upper level of Cabeço de Porto Marinho I and Lapa dos Coelhos Layer 4.

\section{Magdalenense final}

A camada 3 da Lapa dos Coelhos e os dois níveis do Abrigo 1 de Vale de Covões são enquadráveis neste período cronológico. Contudo, o efectivo analisado contrasta em termos numéricos: 357 peças da Lapa dos Coelhos e apenas 59 do Abrigo 1 de Vale de Covões (16 peças da camada 3 e 43 da camada 4). No conjunto do Abrigo 1 de Vale de Covões a maioria dos talões é de tipo esmagado (34\% para a C3 e 20\% para a C4) e punctiforme (22\% para a C3 e 34\% para a C4). A abrasão é quase sempre ligeira e está presente em cerca de $30 \%$ das peças (31\% para C3 e 26\% para a C4). O labiado está presente em $42 \%$ das peças da C4 e apenas em $13 \%$ das peças da C3. A fissuração do cone de percussão, o esquirolamento do bolbo e a linha de talão irregular foram identificados mas num limitado número de peças. $\mathrm{O}$ reduzido conjunto proveniente do Abrigo 1 de Vale Covões obriga ao tratamento destes dados com algumas reservas mas parece-nos seguro afirmar a existência de indícios que documentam a utilização esporádica de um percutor mineral brando, num contexto de maioritária utilização de um percutor brando orgânico. As peças recuperadas na camada 3 da Lapa dos Coelhos apresentam sobretudo talões de tipo liso (28\%) e linear (24\%) (Figura 5). A utilização da abrasão foi posta em evidência em $40 \%$ das peças (em $6 \%$ trata-se de uma ligeira abrasão) e o labiado ocorre em $17 \%$ dos exemplares. O esquirolamento do bolbo existe em 5\% das peças (Figuras 6 e 7), foi notada uma fissuração do cone de percussão (Figura 8) em $5 \%$ das lamelas observadas e rugas finas concêntricas a partir do cone de percussão (Figura 9) em 5 exemplares (1\%). A linha irregular do talão foi identificada em 5 peças (1\%). Neste caso parece-nos seguro avançar uma utilização efectiva de percutor em pedra branda. 


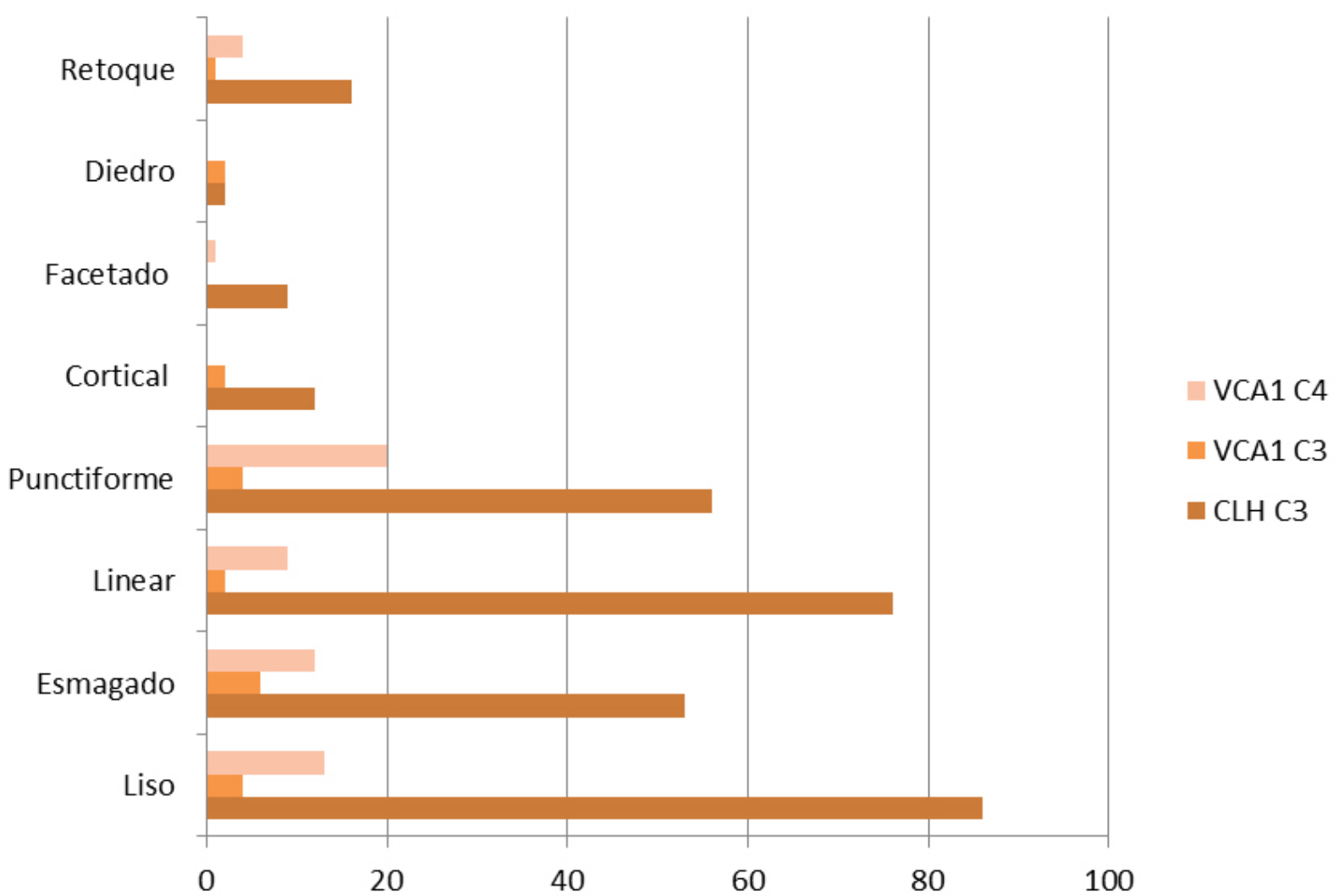

Figura 5. Magdalenense final : tipos de talão identificados nos conjuntos líticos da camada 3 da Lapa dos Coelhos e das camadas 3 e 4 do Abrigo 1 de Vale Covões.

Figure 5. Upper Magdalenian: butt types identified in the lithic assemblage of Lapa dos Coelhos Layer 3 and Layers 3 and 4 from Abrigo 1 de Vale Covões.
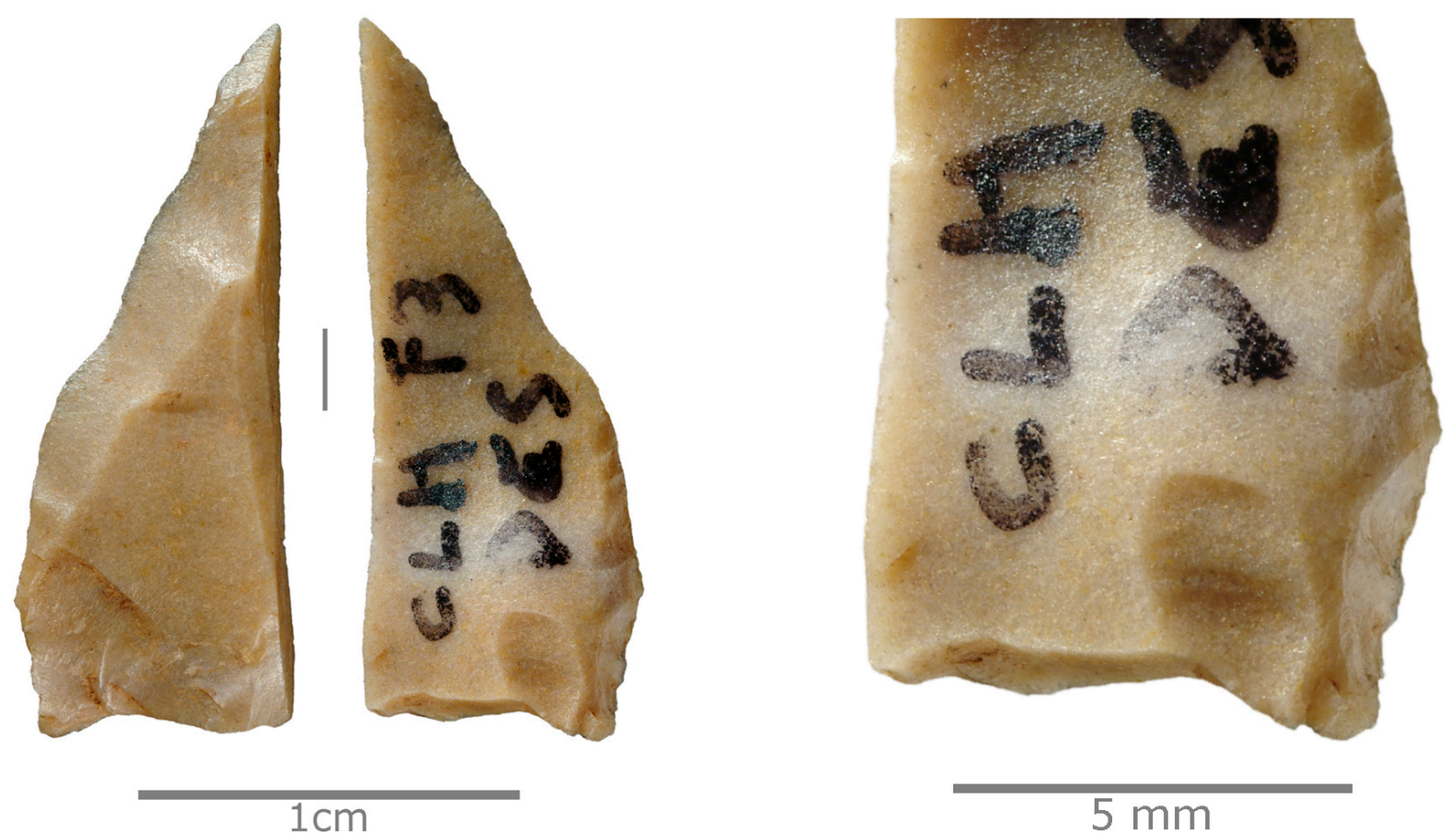

Figura 6. Lapa dos Coelhos, camada 3: A - Lamela com retoque marginal inverso; B - Detalhe do esquirolamento do bolbo (Fotos de J. P. Ruas).

Figure 6. Lapa dos Coelhos, camada 3: A - Marginal, inverse retouch bladelet; B - Detail showing splintering of the butt (Photos by J. P. Ruas). 


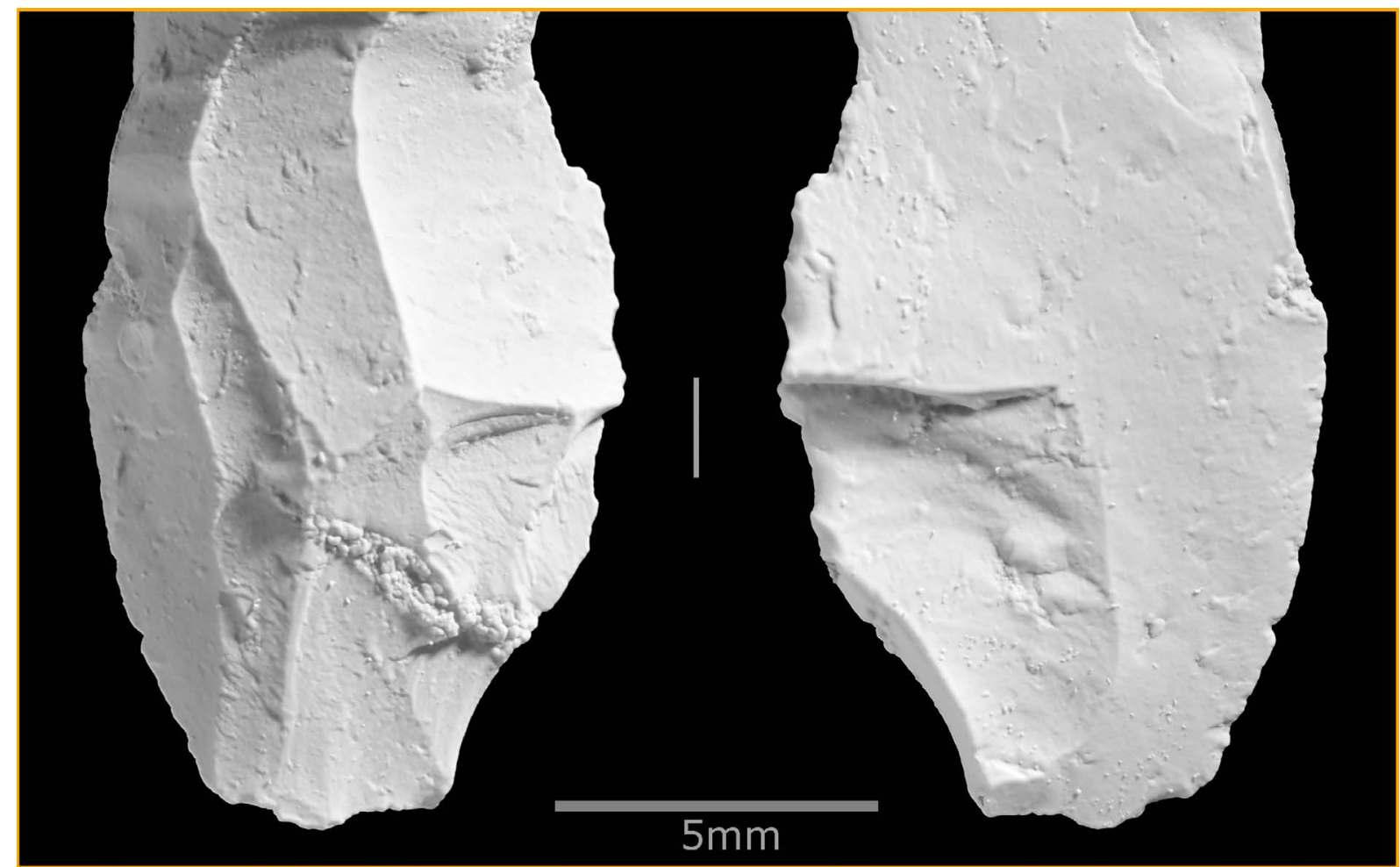

Figura 7. Lapa dos Coelhos, camada 3: lamela com esquirolamento do bolbo, evidenciado por pulverização com óxido de magnésio (Foto de J. P. Ruas).

Figure 7. Lapa dos Coelhos, layer 3: bladelet presenting splintering of the butt evidenced by covering with magnesium oxide (Photo by J. P. Ruas).

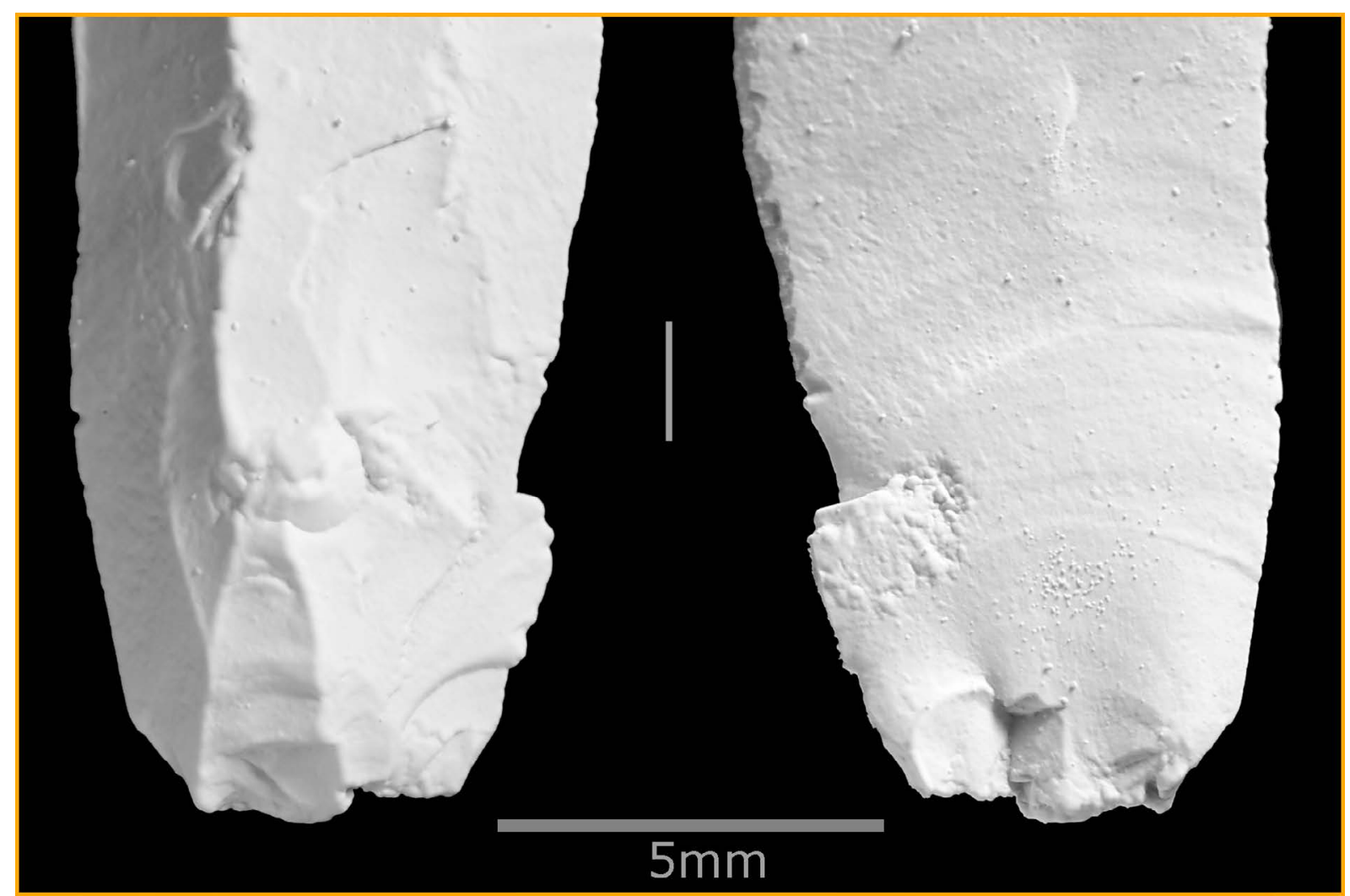

Figura 8. Lapa dos Coelhos, camada 3: lamela com linha do talão irregular com dois pontos de contacto, evidenciados por pulverização com óxido de magnésio (Foto de J. P. Ruas).

Figure 8. Lapa dos Coelhos, layer 3: bladelet presenting a crack or irregular line butt and double contact points evidenced by covering with magnesium oxide (Photo by J. P. Ruas). 


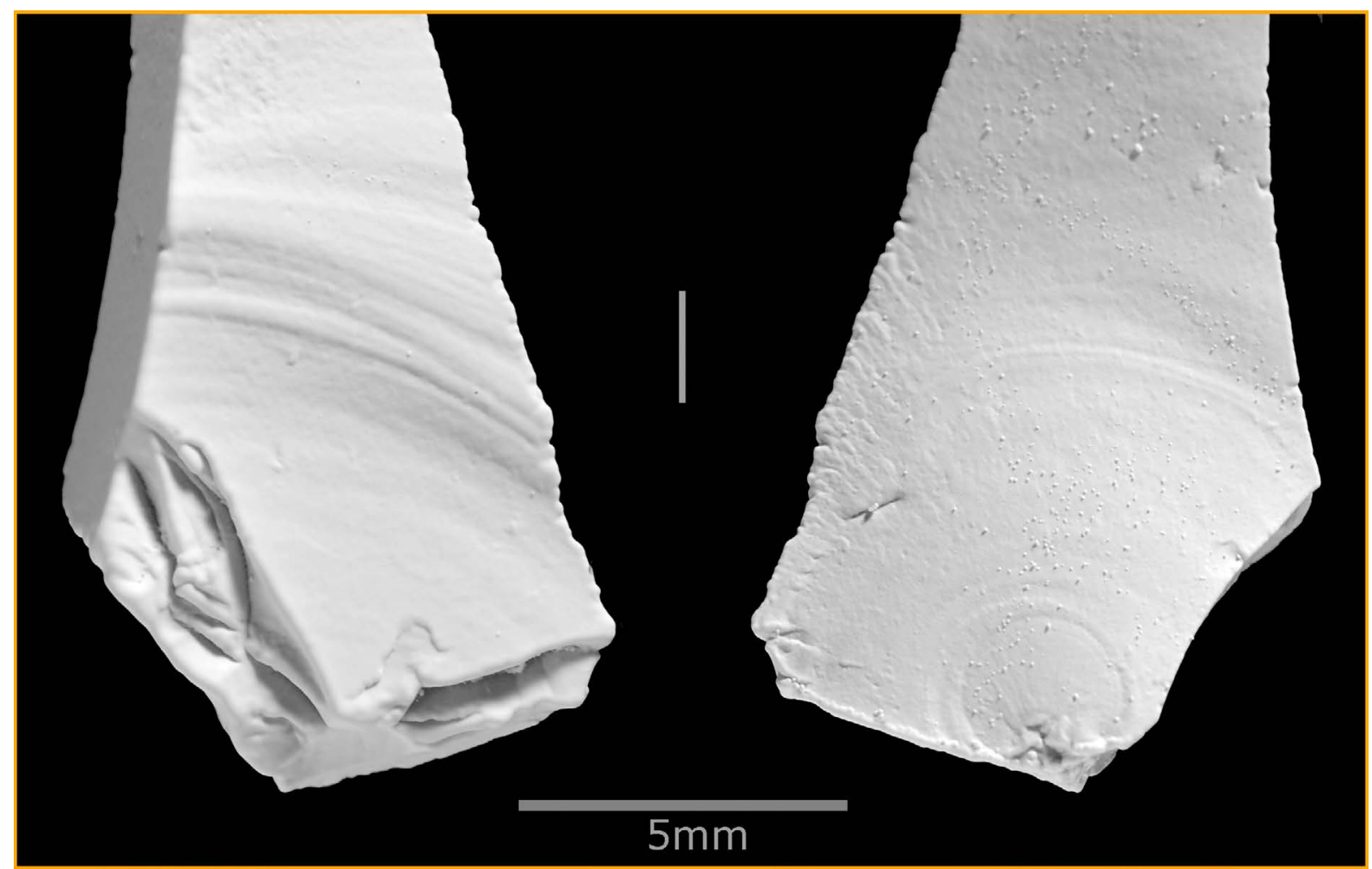

Figura 9. Lapa dos Coelhos, camada 3: lamela com rugas finas concêntricas partindo do ponto de impacto evidenciadas por pulverização com óxido de magnésio (Fotos de J. P. Ruas).

Figure 9. Lapa dos Coelhos, layer 3: bladelet presenting concentric wrinkles starting from the impact point evidenced by covering with magnesium oxide (Photo by J. P. Ruas).

\section{Discussão e conclusões}

Partindo da análise de colecções de talhe experimental, J. Pelegrin (2000) descreveu as características da percussão com percutor em pedra branda, distinguindo duas versões desta técnica: uma mais próxima da percussão directa dura e outra que pode substituir um percutor orgânico. A segunda versão aproxima-se do que identificamos para a debitagem lamelar no Magdalenense. Com esta técnica é possível utilizar o percutor em pedra branda da mesma forma que um percutor orgânico: usando um ângulo mais aberto e percutindo mais perto do bordo do plano de percussão, originando talões muito finos (Pelegrin 2000: 78).

A identificação fortuita de atributos evocativos da utilização de percutores em pedra branda na colecção lítica da camada 3 da Lapa dos Coelhos, conduziu a um registo sistemático desses mesmos estigmas, durante o estudo de outras colecções magdalenenses da Estremadura portuguesa. A amostra analisada é constituída por 1303 peças, no entanto, os conjuntos são díspares em termos numéricos: cerca de 85\% das lamelas observadas provêm da camada 3 da Lapa dos Coelhos e do nível superior do Cabeço de Porto Marinho I, respectivamente datando do Magdalenense final e do Magdalenense superior (Tabela 3). Os restantes conjuntos são constituídos por um número pouco significativo de peças. Os dados apresentados evidenciam a utilização de percutores brandos (orgânicos ou minerais) para a debitagem de suportes lamelares durante o Magdalenense na Estremadura: percentagens de abrasão (ligeira ou marcada) e de labiado na ordem dos 40\% (Tabela 4). Em proporções variáveis, mas sempre presentes, identificámos estigmas diagnósticos associados à utilização de percutores minerais brandos: fissuração do cone de percussão, esquirolamento do bolbo, linha do talão irregular e rugas finas e concêntricas a partir do ponto de impacto (Tabela 5). Segundo Pelegrin (2000) a ocorrência destes estigmas é reduzida (na ordem dos 20\%) e variável. 
Tabela 3. Número de lamelas analisadas e subdivisão por peças sem retoque (brutas) e retocadas. VCA1 - Abrigo 1 de Vale Covões; CLH - Lapa dos Coelhos; CPM I - Cabeço de Porto Marinho I. * - Incluindo lamelas de buril Table 3. Number of analyzed bladelets (unretouched and retouched). VCA1 - Abrigo 1 de Vale Covões; CLH Lapa dos Coelhos; CPM I - Cabeço de Porto Marinho I.*- Including burin spalls.

\begin{tabular}{lccc}
\hline & \multicolumn{2}{c}{ Efectivos analisados } & \\
Proveniência & Lamelas brutas* & Lamelas retocadas & Total \\
\hline CLH - Camada 3 & 238 & 119 & 357 \\
CLH - Camada 4 & 50 & 7 & 57 \\
CPM - Nível Sup & 607 & 121 & 728 \\
CPM - Nível Inf. & 83 & 19 & 102 \\
VCA1 - Camada 3 & 13 & 3 & 16 \\
VCA1 - Camada 4 & 35 & 8 & 43 \\
\hline Total & $\mathbf{1 0 2 6}$ & $\mathbf{2 7 7}$ & $\mathbf{1 3 0 3}$ \\
\hline
\end{tabular}

Tabela 4. Número e percentagem de peças apresentando vestígios de abrasão (ligeira e evidente) e labiado. VCA1 - Abrigo 1 de Vale. Covões; CLH - Lapa dos Coelhos; CPM I - Cabeço de Porto Marinho I.

Table 4. Number and percentage of pieces presenting traces of abrasion (slight and marked) and lip. VCA1 Abrigo 1 de Vale. Covões; CLH - Lapa dos Coelhos; CPM I - Cabeço de Porto Marinho I.

\begin{tabular}{|c|c|c|c|c|c|c|}
\hline \multirow[b]{2}{*}{ Proveniência } & \multicolumn{2}{|c|}{ Abrasão ligeira } & \multicolumn{2}{|c|}{ Abrasão } & \multicolumn{2}{|c|}{ Labiado } \\
\hline & № & $\%$ & № & $\%$ & № & $\%$ \\
\hline CLH - Camada 3 & 20 & 6 & 122 & 34 & 60 & 17 \\
\hline CLH - Camada 4 & 22 & 39 & 14 & 25 & 33 & 58 \\
\hline CPM - Nível Sup & 239 & 33 & 62 & 9 & 469 & 64 \\
\hline CPM - Nível Inf. & 27 & 26 & 22 & 22 & 42 & 41 \\
\hline VCA1 - Camada 3 & 5 & 31 & 1 & 6 & 2 & 13 \\
\hline VCA1 - Camada 4 & 11 & 26 & 5 & 12 & 18 & 42 \\
\hline
\end{tabular}

Tabela 5. Número e percentagem de peças apresentando estigmas relacionáveis com a utilização de um percutor em pedra branda: fissuração do cone de percussão, esquirolamento do bolbo, linha do talão irregular e rugas finas concêntricas a partir do ponto de impacto (Pelegrin, 2000). VCA1 - Abrigo 1 de Vale Covões; CLH - Lapa dos Coelhos; CPM I - Cabeço de Porto Marinho I.

Table 5. Number and percentage of pieces presenting stigmata related to the use of a soft hammerstone: percussion cone cracking, splintering of the butt, irregular bead line and fine concentric wrinkles starting from the impact point VCA1 - Abrigo 1 de Vale. Covões; CLH - Lapa dos Coelhos; CPM I - Cabeço de Porto Marinho I.

\begin{tabular}{|c|c|c|c|c|c|c|c|c|}
\hline \multirow[b]{2}{*}{ Proveniência } & \multicolumn{2}{|c|}{$\begin{array}{l}\text { Fissuração do } \\
\text { cone percussão }\end{array}$} & \multicolumn{2}{|c|}{$\begin{array}{c}\text { Esquirolamento } \\
\text { do bolbo }\end{array}$} & \multicolumn{2}{|c|}{$\begin{array}{l}\text { Linha do talão } \\
\text { irregular }\end{array}$} & \multicolumn{2}{|c|}{$\begin{array}{c}\text { Rugas finas } \\
\text { concêntricas a partir } \\
\text { do ponto de impacto }\end{array}$} \\
\hline & № & $\%$ & № & $\%$ & № & $\%$ & № & $\%$ \\
\hline CLH - Camada 3 & 18 & 5 & 17 & 5 & 5 & 1 & 5 & 1 \\
\hline CLH - Camada 4 & & & 4 & 7 & & & & \\
\hline CPM - Nível Sup & 215 & 30 & 127 & 17 & 6 & 1 & 4 & 4 \\
\hline CPM - Nível Inf. & 8 & 8 & 20 & 20 & 2 & 2 & & \\
\hline VCA1 - Camada 3 & 1 & 6 & 2 & 13 & 1 & 6 & & \\
\hline VCA1 - Camada 4 & 1 & 2 & 1 & 14 & 1 & 2 & & \\
\hline
\end{tabular}


A utilização de percutor mineral brando foi referida em contextos de debitagem lamelar utilizando núcleos carenados durante a fase recente do Protosolutrense (Aubry et al. 1998) e não dispomos de dados para comparar com outras cronologias ao longo do Paleolítico Superior regional. Contudo, na amostra estudada, a utilização de um percutor de pedra branda parece ter aumentado a partir do Magdalenense final. Tal facto parece ser confirmado pelo contraste entre a camada 3 e a camada 4 da Lapa dos Coelhos. Como estamos perante cadeias operatórias curtas, sem grandes operações de preparação e manutenção, e usando pequenos volumes parece-nos seguro avançar que este tipo de percutor poderá ter sido utilizado sistematicamente durante toda a cadeia operatória. Com excepção do Magdalenense antigo, a maioria da estratégia de debitagem de produção de suportes lamelares é sobre aresta de lasca uma opção que permite uma produção bastante estandardizada (a largura das lamelas é a própria espessura da lasca mãe) pelo que não podemos associar as características morfométricas exclusivamente ao tipo de percussão.

Noutras regiões com substratos litológicos diferentes da Estremadura, como a Bacia do Guadiana, no Sul, ou o Vale do Côa, no Norte, ambas áreas com rochas metamórficas, as colecções incluem poucas peças em sílex (Gameiro 2012; Almeida et al. 2013). Em relação aos sítios da Bacia do Guadiana, estes não foram incluídas no presente trabalho, não só pela reduzida dimensão dos conjuntos lamelares e porque grande parte das peças é produzida em quartzo, mas também porque não foi possível efectuar datações absolutas e portanto subsistem dúvidas quanto à sua cronologia. Contudo, tanto na Malhada do Mercador como no Monte da Ribeira, ambos na Bacia do Guadiana, alguns indícios apontam para a existência de utilização de percutor brando não só orgânico mas também mineral (Gameiro 2012; Almeida et al. 2013). No Monte da Ribeira, que poderá ter uma cronologia do Magdalenense antigo existem algumas (raras) peças evocativas de percussão branda mineral mas na Malhada do Mercador, um sítio provavelmente do Magdalenense final, cerca de 30\% das peças brutas e $22 \%$ das peças retocadas apresentam esquirolamento do bolbo (num conjunto lítico de menos de 20 peças). No Vale do Côa, nos sítios com esta cronologia impera a utilização do quartzo e a debitagem bipolar sobre bigorna ou tipo peça esquirolada predomina (Aubry et al. 1998; Gameiro, 2009).

Que vantagem possibilitará a utilização de um percutor em pedra branda que justifique um aumento da sua utilização durante o Magdalenense final? Segundo Pelegrin (2000) não existem vantagens comparativamente ao uso de um percutor orgânico: a execução técnica não é mais fácil, a abrasão é quase obrigatória, portanto há necessidade de preparar o volume a debitar e a sua utilização pode ser difícil em matérias-primas mais grosseiras. Assim sendo, poderá haver alguma motivação económica? O ambiente litológico da Estremadura torna fácil a obtenção de percutores de calcário, de sílex com córtex espesso, de grés ou arenito. Por outro lado, sabemos que ao longo do Tardiglaciar terá ocorrido uma diminuição na captura e consumo de animais de médio e grande porte e um aumento do consumo de animais de pequeno porte (Bicho et al. 2000; Bicho et al. 2011; Davis 2002; Gameiro et al. 2017). Poderá este facto explicar a dificuldade em obter, e transformar em percutor, hastes de cervídeo, por exemplo? Pelegrin (2000) avançou como hipótese uma eventual relação com alterações nas estratégias de caça: durante o Tardiglaciar as armaduras voltam a ser equipadas com pontas líticas e não em osso o que terá originado uma necessidade de produzir mais micrólitos. Ao longo do Tardiglaciar, na Estremadura portuguesa sabemos que, não só aumenta a diversidade tipológica, mas também a quantidade de armaduras (Zilhão 1997; Bicho 1997; 2000; Gameiro 2012). Parece-nos plausível, mas impossível de demonstrar, que estes dados de cariz económico se articulem com a escolha preferencial de um tipo de percutor. A utilização fortuita e expeditiva de um recurso natural de fácil acesso pode ter motivado e condicionado uma opção cultural. 
A identificação das técnicas de percussão abrange um elemento descritivo importante das opções técnicas efectuadas pelos talhadores no passado e podemos concluir que o reconhecimento, que aqui documentamos, da utilização de percutores em pedra branda constitui mais uma achega para melhor apreender a diversidade cultural do Tardiglaciar no Centro de Portugal.

\section{Agradecimentos}

Este trabalho baseia-se em dados obtidos durante a elaboração de uma tese de doutoramento dirigida por Nicole Pigeot e financiada pela Fundação para a Ciência e Tecnologia (SFRA/BD/6709/2001). Agradecemos a Jacques Pelegrin e a Boris Valentin o precioso auxílio na aprendizagem do reconhecimento dos estigmas típicos deste tipo de percussão. Agradecemos a Thierry Aubry a elaboração de algumas peças em talhe experimental assim como o frequente esclarecimento de dúvidas e troca de ideias. Agradecemos os comentários e sugestões de Ana Cristina Araújo, Francisco Almeida, João Zilhão e Laurent Klaric durante o estudo das colecções. As fotos apresentadas são da autoria de José Paulo Ruas, a quem agradecemos.

\section{Referencias}

Almeida, F., Angelucci, D., Gameiro, C., Correia, J., Pereira, T. 2004, Novos dados para o Paleolítico Superior final da Estremadura Portuguesa: resultados preliminares dos trabalhos arqueológicos de 1997-2003 na Lapa dos Coelhos (Casais Martanes, Torres Novas). Promontoria, 2(2): 157-192. (in Portuguese) ("New data on the final upper Paleolithic of the Portuguese Estremadura: preliminary results of the archaeological work during 1997-2003 at Lapa dos Coelhos (Casais Martanes, Torres Novas)”)

Almeida, F., Araújo, A. C., Aubry, T. 2003, Paleotecnologia lítica: dos objectos aos comportamentos. In: Paleoecologia Humana e Arqueociências. Um programa Multidisciplinar para a Arqueologia sob a tutela da cultura (Mateus, J. \& MorenoGarcia, M., Eds), Instituto Português de Arqueologia, Lisboa: p. 299-349. (in Portuguese) ("Lithic paleotechnology: from objects to behaviors”)

Almeida, F., Gameiro, C. Pereira, T., Quelhas, A. 2013, O Paleolítico Superior. In: Testemunhos do Paleolítico no Regolfo de Alqueva. Resultados do Bloco 1 do Plano de Minimização de impactes sobre o Património Arqueológico (Almeida, F., Ed.), Empresa de Desenvolvimento e Infraestruturas do Alqueva (EDIA), Beja: p. 93-250. (in Portuguese) ("Paleolithic evidences in the area of Alqueva dam. Block 1 results: plan for Minimizing Impacts on the Archaeological Heritage”)

Aubry, T., Gameiro, C., Mangado Llach, J., Luís, L., Matias, H. \& do Pereiro, T. 2016, Upper Palaeolithic lithic raw material sourcing in Central and Northern Portugal:

Reconstructing Long Distance Social Networks. Journal of Lithic Studies, 3(2): 22 p. (em inglês) (“Aprovisionamento de matéria-primas líticas no Paleolítico Superior do Centro e Norte de Portugal: reconstrução de redes sociais de longa distância”) doi:10.2218/jls.v3i2.1436

Aubry, T., Zilhão, J., Almeida, F., Fontugne, M. 1998, Production d'armatures microlithiques pendant le Paléolithique supérieur et le Mésolithique au Portugal. Actas del II Congresso de Arqueologia Peninsular, Fundación Rei Afonso Henriques, Zamora: p. 259-272. (em francês) (“ Produção de armaduras microlíticas durante o Paleolítico Superior e Mesolítico em Portugal”) 
Bachellerie, F., Bordes, J.-G., Morala, A., Pelegrin, J. 2007, Étude typo-technologique et spatiale de remontages lithiques de Canaule II, site châtelperronien de plein-air en Bergeracois (Creysse, Dordogne). Paleo, 19: 259-280. (em francês) ("Estudo tipotecnológico e espacial das remontagens líticas de Canaule II, sítio Castelperronense de ar livre em Bergeracois (Creysse, Dordogne)”) URL: http://journals.openedition.org/paleo/782

Bicho, N. 1997, Spacial, technological, and economic organization after the Last Glacial Maximum in Portuguese Prehistory. In: El món mediterrani desprès del pleniglacial (18 000-12 000) (Fullola, J., \& Soler, N., Eds), Museu d'Arqueologia de Catalunya, Girona: p. 213-223. (em inglês) ("Organização espacial, tecnologia e economia depois do último máximo glacial na pré-história portuguesa”)

Bicho, N. 2000, Technological change in the final upper paleolithic of Rio Maior. Arkeos,Tomar, 454 p. (em inglês) (“Alterações tecnológicas no final do Paleolítico Superior em Rio Maior”)

Bicho, N., Hockett, B., Haws, J., Belcher, W. 2000, Hunter-gatherer subsistence at the end of the Pleistocene: preliminary results from Picareiro cave, Central Portugal. Antiquity, 74(285): 500-506. (em inglês) ("Subsistência dos caçadores-recolectores do final do Pleistocénico: resultados preliminares da gruta do Picareiro”) doi:10.1017/S0003598X00059834

Bicho, N., Haws, J., Almeida, F. 2011, Hunter-gatherer adaptations and the Youger Dryas in central and Southern Portugal. Quaternary International, 242: 336-347. (em inglês) (“Adaptações dos caçadores-recolectores e o Dryas recente no centro e sul de Portugal”) doi:10.1016/j.quaint.2010.12.025

Bodu, P. 2000, Que sont devenues le Magdaléniens du Bassin Parisien ? Quelques éléments de réponses sur le gisement Azilien du Closeau (Rueil-Malmaison, France) In: L'Europe Centrale et Septentrionale au Tardiglaciaire. Actes de la table-ronde internationale (Christensen, M., Valentin, B., \& Bodu, P., Eds), Mémoires du Musée de Préhistoire d'Ile-de-France, Éd. Association pour la promotion de la recherche archéologique en Îlede-France (APRAIF), Nemours: p. 315-339. (em francês) (“Quais os sucessores dos Magdalenenses da Bacia Parisiense? Algumas respostas no sítio Azilense do Closeau (Rueil-Malmaison, França)”)

Bordes, F. 1947, Étude comparative des différentes techniques de taille du silex et des roches dures. L'Anthropologie, 51: 1-29. (em francês) ("Estudo comparativo das diferentes técnicas de talhe do sílex e das rochas duras”)

Bordes, F. \& Crabtree, D. E. 1969, The Corbiac blade technique and other experiments. Tebiwa, the journal of Idaho State University Museum, 12(2): 1-21. (em inglês) (“A técnica da lamina de Corbiac e outras experimentações”)

Damlien, H. 2015, Striking a difference? The effect of knapping techniques on blade attributes. Journal of Archaeological Science, 63: 122-135. (em inglês) ("Diferença marcante? O efeito das técnicas de talhe nos atributos das lâminas”) doi:10.1016/j.jas.2015.08.020

Davis, S.J.M. 2002, The mammals and birds from the Gruta do Caldeirão, Portugal. Revista Portuguesa de Arqueologia, 5: 29-98. (em inglês) ("Os mamíferos e os pássaros da Gruta do Caldeirão, Portugal”) 
Dibble, H., Pelcin, A.1995, The effect of hammer mass and velocity on flake mass. Journal of Archaeological Science, 22: 429-439. (em inglês) ("O efeito da massa e velocidade do percutor na massa das lascas”) doi:10.1006/jasc.1995.0042

Gameiro, C. 2003, L'industrie lithique de la couche 3 de Lapa dos Coelhos (Torres Novas, Portugal). L'usage des matières premières et la spécificité du débitage lamellaire dans le Magdalénien Final de l'Estremadura portugaise. Tese de DEA - UFR 03 Histoire de l'art et Archéologie, Université de Paris I Panthéon-Sorbonne, Paris, 67 p. (em francês) ("The stone tool assemblage from layer 3 of Lapa dos Coelhos (Torres Novas, Portugal). Raw-material usage and particularities of bladelet production during Final Magdalenian of Portuguese Estremadura”)

Gameiro, C. 2007, Bladelet debitage and microlith production during the Portuguese Tardiglacial. Presentation of a program for the revision of the available data. In: From the Mediterranean basin to the Portuguese Atlantic shore: papers in honor of Anthony Marks. Actas do IV Congresso de Arqueologia Peninsular, Universidade do Algarve: Faro: p. 173-184. (em inglês) ("Debitagem lamelar e produção de micrólitos durante o tardiglaciar em Portugal. Apresentação de um programa para a revisão dos dados existentes”)

Gameiro, C. 2009, Utensílios e suportes microlíticos do Magdalenense final no Vale do Côa: o exemplo da U.E. 4 do Fariseu. In: 200 séculos da História do Vale do Côa: incursões na vida quotidiana dos caçadores-artistas do Paleolítico (Aubry, T., Ed), Trabalhos de Arqueologia Vol. 52, Instituto de Gestão do Património Arquitectónico e Arqueológico (IGESPAR), Lisboa: p. 256-268. (in Portuguese) (“Tools and microlithic blanks from final Magdalenien at the Côa Valley: the example of the U.E.4 at Fariseu”)

Gameiro, C. 2012, La variabilité régionale des industries lithiques de la fin du Paléolithique supérieur au Portugal. Tese de Doutoramento, UFR 03 Histoire de l'art et Archéologie, Université de Paris I Panthéon-Sorbonne, Paris, 485 p. (em francês) ("Regional variability of lithic industries at the end of the Upper Paleolithic in Portugal”) URL: http://www.academia.edu/3154767

Gameiro, C., Almeida, F. 2004, A ocupação da camada 3 da Lapa dos Coelhos (Casais Martanes, Torres Novas). Novos elementos sobre a produção de suportes lamelares durante o Magdalenense Final da Estremadura Portuguesa. Promontoria. 2(2): 193-238. (in Portuguese) ("Layer 3 human ocupation at Lapa dos Coelhos (Casais Martanes, Torres Novas). New elements on the bladelet production during final Magdalenien of portuguese Estremadura”)

Gameiro, C., Aubry, T., Almeida, F. 2008, L’exploitation des matières premières au Magdalénien Final en Estremadura portugaise : données des sites de Lapa dos Coelhos et de l'Abrigo dos Covões. In: Espace et temps: Quelles diachronies, quelles synchronies, quelles échelles? Procedings of the UISPP meeting (4-9 Setembro, Lisboa, 2006) (Aubry, T., Almeida, F., Araújo, A. C., \& Tiffagom, M., Eds.). BAR International Series Vol. 1831, Archaeopress, Oxford: p. 57-68. (em francês) (“A exploração das matérias-primas no Magdalenense final da Estremadura portuguesa: dados da Lapa dos Coelhos e do Abrigo dos Covões”)

Gameiro, C., Davis, S., Almeida, F. 2017, A sequência estratigráfica da Lapa dos Coelhos: funcionalidade e subsistência ao longo do pleistocénico superior no sopé na Serra de Aire (Portugal), Actas do II Congresso da Associação Portuguesa de Arqueólogos, Associação Portuguesa de Arqueólogos (AAP), Lisboa: p. 357-374. (in Portuguese) 
(The stratigraphic sequence of the Lapa dos Coelhos: functionality and subsistence along the upper Pleistocene at Serra d'Aire (Portugal)”)

Gibaja, J.F. \& Carvalho, A.F., 2012, Introdução ao Estudo da Pedra Lascada, Edições Colibri, Lisboa, 108 p. (in Portuguese) ("Introduction to lithic analysis")

Inizan, M.L., Reduron, M., Roche, H., Tixier, J. 1995, Technologie de la pierre taillée. Cercle de Recherches et d'Études Préhistoriques (CREP), Meudon, 199 p. (em francês) (“ Tecnologia da pedra talhada”)

Klaric, L. 2003, L'unité technique des industries à burins du raysse dans leur contexte diachronique. Réflexions sur la diversité culturelle au Gravettien à partir des données de la Picardie, D’Arcy-Sur-Cure, de Brassempouy et du Cirque de la Patrie. Tese de Doutoramento, UFR 03 Histoire de l'art et Archéologie, Université de Paris I PanthéonSorbonne, Paris, 485 p. (em francês) (“A unidade tecnica das indústrias com burins do Raysse no seu contexto diacrónico. Reflexões sobre a diversidade cultural no Gravetense a partir dos dados da Picardie, de Arcy-Sur-Cure, de Brassempouy e do Cirque de la Patrie”)

Marks, A., Bicho, N., Zilhão, J., Ferring, C. 1994, Upper pleistocene Prehistory in Portuguese Estremadura: results of preliminary research. Journal of Field Archaeology, 21: 53-68. (em inglês) ("Pré-história do Pleistocénico superior na Estremadura portuguesa: resultados preliminaries”)

Marks, A., Mishoe, M. 1997, The Magdalenian of Portuguese Estremadura In: El món mediterrani desprès del pleniglacial (18 000-12 000) (Fullola, J., \& Soler, N. Eds.), Museu d'Arqueologia de Catalunya, Girona: p. 225-232. (em inglês) ("O Magdalenense da Estremadura portuguesa”)

Pelegrin, J. 2000, Les techniques de débitage laminaire au Tardiglaciaire: critères de diagnose et quelques réflexions. In: L'Europe Centrale et Septentrionale au Tardiglaciaire. Actes de la table-ronde internationale (Christensen, M., Valentin, B., \& Bodu, P., Eds.), Mémoires du Musée de Préhistoire d'Ile-de-France, Éd. Association pour la promotion de la recherche archéologique en Île-de-France (APRAIF), Nemours: p. 73-86. (em francês) (“As técnicas de debitagem laminar durante o tardiglaciar: critérios de diagnóstico e algumas reflexões”)

Pelegrin, J., Inizan, M-L. 2013, Soft hammerstone percussion use in bidirectional blade-tool production in Acila 36 and in bifacial knapping at Shagra (Qatar). Arabian Archaeology and Epigraphy, 2013(24): 79-86. (em inglês) ("Utilização do percutor de pedra branda na produção bidireccional de lâminas em Acila 36 e no talhe bifacial em Shagra (Qatar)")

Renard, C. 2002, Des témoins solutréens en France Septentrionale : un mode original de production des supports à face plane (La Celle-Saint Cyr, Yonne). Bulletin de la Société Préhistorique Française, 99(3): 461-485. (em francês) ("Testemunhos solutrenses na França setentrional: um modo original de produção de suportes de face plana”) doi:10.3406/bspf.2002.12708

Tixier, J. 1967, Procèdes d'analyse et questions de terminologie dans l'étude des ensembles industriels du Paléolithique récent et de l’Épipaléolithique en Afrique du Nord-Ouest. In: Background to evolution in Africa (Bishop, W.W., \& Clark, J.D., Eds.), The University of Chicago Press, Chicago: p. 771-820. (em francês) ("Procedimentos de análise e questões de terminologia no estudo das industrias do Paleolítico recente e do Epipaleolítico na África do Noroeste”) 
Tixier, J., Inizan, M.L., Roche, H. 1980, Préhistoire de la pierre taillée. 1- Terminologie et technologie, Cercle de Recherches et d'Études Préhistoriques (CREP), Antibes: p. 199 (em francês) ("Préhistória da pedra talhada. 1 - Terminologia e tecnologia")

Valentin, B. 2000, L'usage des percuteurs en pierre tendre pour le débitage des lames. Circonstances de quelques innovations au cours du Tardiglaciaire dans le Bassin parisien, In: Le Paléolithique supérieur récent : nouvelles données sur le peuplement et l'environnement (Pion, G., Ed.), Actes de la table ronde de Chambéry, Mémoire de la Société préhistorique française Vol. 28, Société préhistorique française, Paris: p. 253260. (em francês) (“A utilização de percutores em pedra branda na debitagem de lâminas. Algumas inovações ao curso do Tardiglaciar na Bacia parisiense”)

Valentin, B. 2008, Jalons pour une paléohistoire des derniers chasseurs (XIV-VI millénaire avant J.-C.). Publications de la Sorbonne, Paris, 325 p. (em francês) ("Jargões para uma Paleohistória dos últimos caçadores (XIV-VI milénios a.C.”)

Zilhão, J. 1997, O Paleolítico Superior da Estremadura Portuguesa. Ed. Colibri, Lisboa, 850 p. (in Portuguese) (“Upper Paleolithic of portuguese Estremadura”)

Zilhão, J. 1997, The Paleolithic settlement of Portuguese Estremadura after the last glacial maximum. In: El món mediterrani desprès del pleniglacial (18 000-12 000) (Fullola, J., Soler, N., Eds.), Museu d'Arqueologia de Catalunya, Girona: p. 233-242. (em inglês) (“O povoamento paleolítico na Estremadura portuguesa depois do último máximo glaciar”) 


\title{
Soft hammerstone percussion use in bladelet debitage during the Magdalenian at Portuguese Estremadura
}

\author{
Cristina Gameiro
}

UNIARQ - Faculdade de Letras da Universidade de Lisboa, Alameda da Universidade, 1600-214 Lisboa, Portugal. Email: gameiro.cristina@gmail.com

\begin{abstract}
:
The development of experimental flint knapping programs allowed for the identification of stigmas related to the use of soft hammerstone percussion. Pelegrin (2000) explored the limits and constraints of the use of this type of percussion and since the first publication of these distinctive stigmas this technique was identified in assemblages from different chronologies in Europe and the Near East. The random identification of stigmata evoking the use of soft hammerstone in the lithic collection of layer 3 of Lapa dos Coelhos led to a systematic registration of certain attributes during the study of other Magdalenian collections of Portuguese Estremadura (Abrigo 1 de Vale de Covões, Cabeço de Porto Marinho). A total of 1303 pieces (complete or proximal fragments) was studied. In terms of methodology, theoretical data and confrontation with experimental knapped series supported our analyses and therefore we systematically recorded the following attributes: butt type (cortical, flat, dihedral, faceted, microfaced, linear, punctiform, crushed and retouched), presence of lip, traces of abrasion (slight or marked), presence of cracking in the percussion cone, existence of fine concentric wrinkles from the percussion bulb and presence of an irregular butt line. The analysis and quantification of these percussion stigmas allowed us to identify a significant number of pieces with evidence of soft hammer (organic and mineral) for bladelet production: the percentage of abrasion (slight or marked) and lip is $40 \%$. In variable proportions, but always present, we identified diagnostic stigmas associated with the use of soft hammerstone percussion: cracking of the percussion cone, scabbing of the bulb, irregular butt line and fine and concentric wrinkles from the percussion cone. According to Pelegrin (2000) the occurrence of these stigmas is reduced (in the order of 20\%) and variable. We conclude that the recurrent association of distinctive characters suggests that the use of soft hammerstone would have been significant. The absence of data from other chronologies doesn't allow for an effective comparison of the Upper Palaeolithic sequence: In the sample observed, however, the use of a soft hammerstone seems to have increased during Final Magdalenian. What advantage in the use of a soft hammerstone justifies an increase of its use during the final Magdalenense? According to Pelegrin (2000) there are no advantages compared to the use of an organic hammer: technical execution is no longer easy, abrasion is almost mandatory, therefore it is necessary to prepare the volume prior to debitage. In this case, could there be any economic motivation? The lithological environment of Estremadura makes it easy to obtain hammers of limestone, flint, or thick sandstone. On the other hand, we know that during the Tardiglacial there was a reduction in the catch and consumption of medium and large animals and an increase in the consumption of small animals (Bicho et al. 2000; Bicho et al. 2011; Davis 2002; Gameiro et al. 2017). Could this explain the difficulty in obtaining, and use as a hammer, cervid rods, for example? Pelegrin (2000) hypothesized an eventual relationship with alterations in hunting strategies: during the Tardiglacial the weapons are equipped with lithic tips, causing a need to produce more lithic barbs. Throughout the Tardiglacial, in Portuguese Estremadura we know that, not only increases the typological diversity, but also the amount of armatures (Zilhão 1997; Bicho 1997; 2000; Gameiro 2012). It seems plausible, but impossible to demonstrate, that these economic data are linked to the
\end{abstract}


preferential choice of a type of hammer. The fortuitous and expeditious use of a natural resource easily accessible may have motivated and conditioned a cultural option. Although the evidence presented is still scarce these data should be considered because it is essential for the reconstitution of the spectrum of technical choices made in the past.

Keywords: Portugal; Magdalenian; bladelet debitage; percussion types; soft hammerstones 